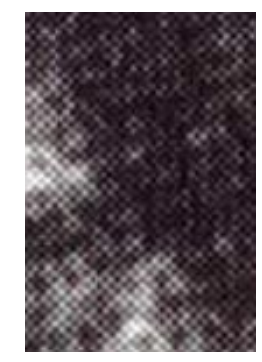

\title{
A natureza do poder: técnica e ação social*
}

Ana Clara Torres Ribeiro ${ }^{1}$

RIBEIRO, A. C. T. The nature of power: technique and social action, Interface _ Comunicação, Saúde, Educação, v.4, n.7, p.13-24, 2000.

This text questions the multiple-meaning character of the network notion, attempting to distinguish the current uses of this notion from those historically formulated by the Social Sciences. Based on this indication, it deals with the network notion by means of two analytical alternatives: the reflection of power and the nature of the social relations encouraged by technical networks. The analysis is carried out largely through a reflection on the sense of social action, with due note being taken of the predominance of instrumental action over radical modernity.

KEY WORDS: Interpersonal relations; technological modernization; computer communication networks; power (Psychology); social change.

O texto interroga o caráter polissêmico da noção de rede, procurando distinguir os usos atuais desta noção dos classicamente formulados pelas Ciências Sociais. Com base nesta indicação, trata a noção de rede por meio de duas opções analíticas: a reflexão do poder e o teor das relações societárias estimuladas pelas redes técnicas. A análise acontece, sobretudo, pela reflexão do sentido da ação social, sendo registrado o predomínio da ação instrumental na modernidade radicalizada.

PALAVRAS-CHAVES: Relações interpessoais; modernização tecnológica; redes de comunicação de computadores; poder (Psicologia); mudança social.

* Apresentado na mesa-redonda "Comunicação e Redes de Poder em Saúde", $2^{\circ}$ Congresso Brasileiro de Ciências Sociais em Saúde, São Paulo, dezembro de 1999.

1 Professora do Instituto de Pesquisa e Planejamento Urbano e Regional da Universidade Federal do Rio de Janeiro (IPPUR/UFRJ); bolsista do Conselho Nacional de Pesquisa (CNPq). <ana_ribeiro@uol.com.br> 
Redes: conexões práticas e analíticas

"Essa transformação de uma fluidez potencial numa fluidez efetiva, por meio da velocidade exarcebada, todavia não tem e nem busca um sentido. Sem dúvida, ela serve ao exercício de uma competitividade desabrida, mas esta é uma coisa que ninguém sabe para o que realmente serve"

(Milton Santos - Por uma outra globalização)
A noção de rede adquire novos conteúdos no mundo contemporâneo, em decorrência, como esclarece Milton Santos (1996), da natureza do novo sistema técnico e do novo sistema de ação. Na verdade, esta noção, conforme hoje utilizada, pressiona anteriores conceitos, expressivos da configuração dos grupos, das interações sociais e do tecido social ${ }^{2}$. Hoje, a noção de rede tende a ser deslocada da referência às relações sociais profundas em direção às mediações entre materialidade e ação social ${ }^{3}$ ou em direção aos elos, permitidos pelas novas tecnologias de informação e comunicação, entre esferas, níveis, instâncias e âmbitos da vida social.

Existe ainda a tendência ao acionamento da noção de rede para indicar uma espécie de supra-sistema de ação, isto é, os vínculos, mais ou menos circunstanciais, que unem formas mais estáveis de organização social, como exemplificariam as redes de movimentos sociais (Scherer-Warren, 1999) ou formatos assumidos pela ação empresarial (Dreifuss, 1996). De fato, a mundialização da economia $e$ as formas supra-nacionais de organização social $e$ política estimulam e apoiam este uso da noção de rede, além dos conteúdos de projetos de modernização que envolvem tanto atores sociais quanto empresas.

Entretanto, raramente se reflete a diferença, de fato existente, entre o uso atualmente predominante da noção de rede, indicativo de formas atualizadas de organização da ação, e aquele que, classicamente, indica a configuração do tecido social, isto é, relações sociais profundas, apenas compreensíveis pela análise do poder. A reflexão articulada destas duas noções de rede estimula, entretanto, a compreensão de que a problemática do poder e da ação social encontram-se presentes em qualquer escala da vida social e em contextos com desiguais níveis de incorporação técnica, em seus vínculos com a cultura e com o território (Randolph, 1998).

Por outro lado, a falta de discernimento entre os dois usos da noção de rede faz com que não ocorra distinção analítica entre formas de agir relacionadas à organização tradicional e cotidiana da vida social, indicadas classicamente por teorias da Antropologia e da Sociologia, e formas de agir expressivas da nova eficácia, da orientação pragmática da ação, atualmente expressa na fugacidade das relações sociais. Nesta última face da noção de rede, surgem questões, nem sempre claras, decorrentes de aproximações analíticas e práticas entre agir econômico e ação social, entre agentes econômicos e sujeitos sociais, fazendo com que a análise das instituições se confunda com características da organização empresarial, como exemplificam as atuais referências ao pósfordismo, no intuito de descrever a totalidade da realidade social.

Aceita-se assim, com facilidade, que análises competentes das novas relações técnicas e sociais de produção sejam transpostas para a reflexão das relações societárias, perdendo-se de vista o estudo dos valores que conduzem à ação social e, ainda, à configuração cultural das relações de poder. O envolvimento
${ }^{2}$ No Concise Oxford Dictionary of Sociology lemos que "O termo rede refere se a indivíduos (e mais raramente coletividades $e$ papéis) que estão ligados por uma ou mais relações sociais, formando uma rede social. Exemplos de relações incluem criação de filhos comunicação, amizade, autoridade e contato sexual".

${ }^{3}$ Weber (1997, p.18) propõe o seguinte conceito de ação social como base para a formulação de tipos ideais articuladores de sua teoria da ação:

"A ação social

(incluindo

tolerância e omissão) se orienta pelas ações de outros, que podem ser passadas, presentes ou esperadas como futuras (vingança por prévios ataques, réplica a ataques presentes, medidas de defesa frente a ataques futuros). Os 'outros' podem ser individualizados $e$ conhecidos ou uma pluralidade de indivíduos indeterminados $e$ completamente desconhecidos (o 'dinheiro', por exemplo, significa um bem - de troca - que o agente admite no intercâmbio porque sua ação está orientada pela expectativa de que muitos outros, agora indeterminadose desconhecidos, estão dispostos a aceitá-lo também, por sua parte, numa troca futura)". 
${ }^{4}$ Morin (1999, p.32) recorda-nos o sentido de paradigma: "A palavra em grego queria dizer 'exemplo', exemplificação quer dizer, um modelo, a estrutura de pensamento que controla todos os pensamentos que daí se originam. Dito de outro modo, o nível paradigmático é o núcleo forte que comanda todos os pensamentos, todas as idéias, todos os conhecimentos que se produzem sob o seu império". dos espaços da reprodução pelas novas tecnologias - o domicílio e o consumo tem permitido que a generalização de tendências sócio-culturais, emanadas da esfera da produção, oriente agilmente a ação social e o estudo da sociedade, fazendo com que se aceite a idéia de que existe um novo paradigma (pósfordista ou pós-moderno) efetivamente catalizador da vida social, inclusive no que concerne às relações sociedade-Estado ${ }^{4}$.

Estranhamente, o denominado pós-fordismo parece oferecer numerosas certezas analíticas ao mesmo tempo que, contraditoriamente, estimula o reconhecimento da indeterminação, da incerteza e do acaso. Neste sentido, poderia ser dito que uma descrição dos processos contemporâneos, construída a partir da ruptura com o passado (o fordismo), adquire a fisionomia de um paradigma que retém a emergência de um nível paradigmático, a ser assumido pelo pensamento social, realmente transformador das formas contemporâneas de compreender a vida coletiva.

Nas palavras de Morin (1996, p.33):

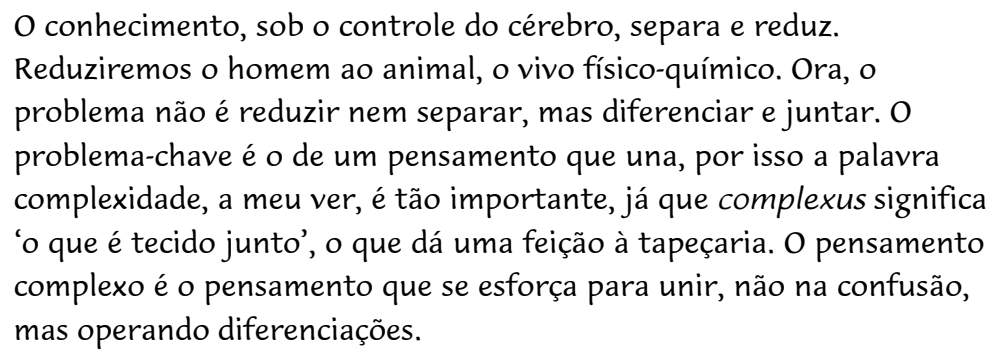

Unir diferenciando e distinguindo, resistir às classificações arbitrárias e às divisões disciplinares arcaicas seriam alguns dos caminhos, propostos por este autor, para o desvendamento de uma nova maneira de conhecer (e de viver).

Tendo em vista esta orientação reflexiva, poderia ser dito que as associações imediatas entre rede técnica e rede social, alimentadas pela indiferenciação entre relações técnicas e sociais de produção e relações societárias ou, ainda, entre rede social primária e rede supra-grupos sociais - cujo conceito ainda precisa ser desenvolvido - reduz a percepção da complexidade do mundo contemporâneo. Entretanto, a complexidade (Morin, 1996) transparece no atual convívio entre fortalecimento de valores tradicionais e formas novíssimas de organização social (Maffesoli, 1997) ou entre a preservação de práticas tradicionais de exercício do poder e acionamento de recursos técnicos atualizados na busca de convencimento ou da legitimidade política.

Como afirmam Pena-Veiga e Pinheiro do Nascimento (1999, p.10) em introdução a livro dedicado à obra de Morin:
Sabemos (...) que nos encontramos atualmente em uma encruzilhada epistemológica e, por isso, as ciências humanas não podem continuar consagrando tanta energia e/ou conhecimento na esperança de reduzir a complexidade do mundo, mesmo que seja pesada e oprimente para nós todos. É impossível, para a ciência, eliminar ou mesmo reduzir a complexidade. Não é possível escondê-la, pois é inerente aos fenômenos.

A redução da complexidade dificulta a análise crítica de alguns fatos de grande relevância cultural e política. Entre estes fatos podem ser citados: (1) - a 
transposição de modelos da gestão privada para a gestão pública, realizada em nome da eficácia e da transparência no uso dos recursos públicos; (2) - a absorção a-crítica, por organizações sociais e pelo Estado, de projetos de modernização que desconhecem a constituição do tecido social (as redes primárias, historicamente constituídas, responsáveis pela consolidação de valores); (3) - o deslocamento radical, como permite reconhecer a obra de Weber (1997), da ação dirigida a valores em direção à ação dirigida a fins.

\section{Redes $e$ ação instrumental}

Este deslocamento da ação dirigida a valores para a ação dirigida a fins ${ }^{5}$ - que se encontra articulado à crise ética contemporânea por expressar a transformação de valores em meios para o alcance de objetivos - tem sido responsável por perdas em sentidos da ação e, desta forma, pelo ativismo como norte da conduta positivamente valorizada. A extensão alcançada por esta orientação é reconhecível em procedimentos institucionais, na difusão de códigos comportamentais no mercado de trabalho, em avaliações de desempenho em práticas profissionais, na programação do lazer e em formas monitoradas de uso dos espaços públicos.

O ativismo, ao significar a absorção da velocidade na ação social, traz, como contrapartida, o aumento do formalismo nas relações societárias. Assim, o ativismo, descolado de transformações sociais amplas, constitui um dos ângulos da crise institucional contemporânea, demonstrando a desconexão entre agir institucional, calcado no formalismo, e comportamentos sociais espontâneos. Como indica Argüello (1999, p.142), ao relembrar a contribuição weberiana à reflexão da modernidade: "Em sua diagnose da modernidade, Weber afirma a inelutabilidade de uma racionalidade estritamente formal peculiar à ordem social moderna (...), racionalidade esta que provoca uma fragmentação entre razão e consciência, e por conseguinte, o domínio de uma razão 'cínica'”.

Por outro lado, estas perdas, observadas em sentidos da ação, correspondem tanto a crises identitárias, inclusive nas profissões, quanto à hegemonia da administração (e da gestão) em instituições públicas e privadas; o que traz, como conseqüência, tendências à burocratização de numerosas práticas sociais. Trata-se, neste momento, da radicalização do denominado racionalismo ocidental, analisado por Weber (Souza, 1999), e, portanto, de processos de ocidentalização do mundo que atingem, com especial força, as sociedades periféricas (Latouche, 1994). Afinal, os formatos assumidos pela ação social correspondem à atualização e/ou ruptura de formas herdadas de organização social.

Assim, a face polissêmica da noção de rede precisa ser efetivamente reconhecida $e$ analiticamente enfrentada. Trata-se de uma noção que, sem dúvida, indica a mudança; podendo ser incorporada, de forma proveitosa, no estudo da desinstitucionalização de relações sociais e de novas formas de organização social. Neste sentido, a rede é, simultaneamente, um instrumento analítico, que necessita ser afinado para o trato de objetos específicos, e uma forma social, articulada a processos concretos de mudança técnica e cultural, de amplas conseqüências sociais.

No entanto, a falta de discernimento entre conceito e fato - permitindo o uso genérico e aparentemente confortável, já que consensual, da noção de rede - tem sido responsável pela incorporação, na produção em Ciências Sociais, de

\footnotetext{
${ }^{5} \mathrm{Na}$ construção dos tipos de ação, Weber (1997, p.21) propõe que: "Atua racionalmente com relação a fins quem orienta sua ação pelo fim, meios e consequências nela implicadas e para o que avalia racionalmente os meios com os fins, os fins com as conseqüências implicadas $e$ os diferentes fins entre si; em todo caso, pois, quem não atue nem afetivamente (emotivamente, em particular) nem orientado pela tradição".
}

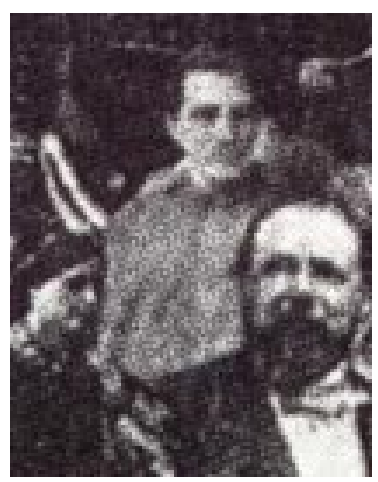


elementos do pragmatismo e do ativismo decorrentes do pensamento único; sendo assim estimuladas transposições a-críticas entre mudança técnica, economia e sociedade. De fato, acontecem, nestas transposições, embricamentos entre projetos de modernização, cujas origens tantas vezes permanecem desconhecidas, e conceito, cujo aprimoramento é contido pela polissemia, possibilitando que a sedução da técnica contemporânea seja transferida à análise da ação social.

Para este texto, optamos por pressionar a noção de rede por meio de dois movimentos analíticos complementares: o primeiro, refere-se à dimensão societária dos projetos contemporâneos de modernização e, o segundo, diz respeito à reflexão do poder, às formas de comando. Procuramos, por esta opção analítica, reduzir o acionamento da noção de rede como metáfora, ou seja, como uma nomeação dos fenômenos sociais que impede a indicação precisa de atividades sociais e econômicas ou que pemite desconhecer a natureza mercantil da técnica e os interesses envolvidos em sua difusão, sempre social e territorialmente seletiva.

\section{Redes: socialidade e poder}

A valorização analítica das relações societárias corresponde à existência, acima referida, de movimentos estruturantes da vida social, configurados por mediações entre escalas, tempos e contextos sociais. Estes movimentos, controlados pelos detentores da técnica, são permitidos e apoiados pela agilização e pela extensão contemporâneas da comunicação e da informação; o que não implica, é claro, a completa desestruturação das esferas vitais articuladas, conectadas, pelas novas tecnologias.

Entretanto, estes movimentos, ao fazerem aflorar um novo tecido social virtual e lacunar, indicam a possível constituição de uma existência social suprainstitucional, correspondendo à necessidade de análise de relações propriamente societárias; análise que subordine, reflexivamente, relações técnicas ao estudo de âmbitos historicamente delimitados das relações sociais. Acredita-se que a noção de rede, deste viés analítico, nomearia, ocultando, uma amplíssima mudança, em curso, na própria configuração do que é sociedade.

A natureza do novo Ser social, difusor permanente de inovações tecnológicas $e$ de formas renovadas de ação, incorpora, transformando, contextos anteriores de organização das relações sociais, merecendo assim, a nosso ver, uma reflexão ética aprofundada, já que sua constituição tem absorvido parcelas crescentes de recursos públicos, inclusive na periferia do capitalismo, de esforços de atualização do tecido social, do trabalho de muitos e de investimentos sociais espontâneos.

Talvez possa ser dito, também, que a ênfase analítica na globalização da economia, isto é, na nova mundialização do capitalismo, ao privilegiar o nível econômico da vida coletiva, dificulta a plena apreensão da natureza do sistema social atualmente em gestação que tem sido indicado, de forma precária, pela idéia de sociedade global. Esta idéia surge do imbricamento entre escala do mercado e escala alcançada por práticas sociais, sendo salientadas $e$ analiticamente valorizadas tendências à padronização cultural $e$ à homogeneização dos costumes.

Entretanto, a emergência de um novo e mais abrangente sistema social implica não apenas na difusão de práticas renovadas de trabalho e consumo; 
mas, sobretudo, no lastreamento de uma forma de agir facilitadora da racionalização das relações sociais e da instauração de um complexo de relações societárias orientado para a eficácia sistêmica. Afinal, o novo sistema é expressivo da modernidade radicalizada (Giddens, 1990) e, como tal, portador de doses acrescidas de racionalidade, inclusive daquele agir racional que encontra-se inscrito e favorecido nas técnicas.

É neste sentido que uma nova e específica noção de rede precisa ser desenvolvida, sendo o próprio nome rede preservado ou não na indicação dos fenômenos expressivos da sistematicidade que hoje transformam instituições $e$ relações sociais em direção ao predomínio da ação instrumental. Nas contundentes palavras de Santos (2000, p.60):

Na verdade, a perversidade deixa de se manifestar por fatos isolados,
atribuídos a distorções da personalidade, para se estabelecer como um
sistema. Ao nosso ver, a causa essencial da perversidade sistêmica é a
instituição, por lei geral da vida social, da competitividade como regra
absoluta, uma competitividade que ocorre sobre todo o edifício social.

Neste sentido, acrescentamos que o privilégio, pela análise, da esfera da produção (conforme o paradigma pós-fordista) ou das redes (numa mescla, ainda pouco clara, com práticas e vivências anteriores ou com a técnica) tem retido a percepção da nova sistematicidade que orienta a ação social, correspondente ao predomínio do pragmatismo nas relações societárias e à instauração de uma velocidade que escapa aos limites humanos e às culturas tradicionais $e$, ainda, ao ritmo necessário à manifestação dos sentimentos e à escolha de valores orientadores da conduta.

Ainda nas palavras de Santos (2000, p.46):
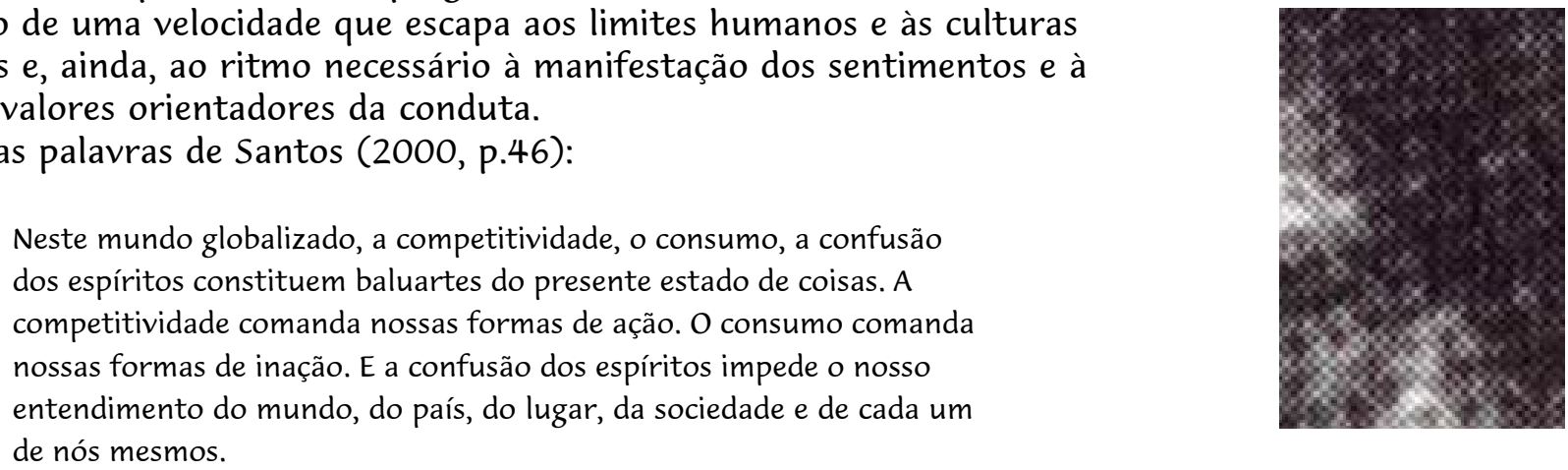

De fato, as mudanças em curso atingem, inclusive, instituições emanadoras de valores como o Estado e a Igreja (Ribeiro e Ribeiro, 1994), exigindo a reflexão daquelas relações que correspondem à sociedade como um todo, às formações sociais.

Não se trata, apenas, da ruptura em fronteiras físicas possibilitada pelas inovações tecnológicas mas, também, de rupturas em instituições historicamente vinculadas à orquestração das relações sociais, seja no sentido da conservação de valores seja no da mudança. Esta observação também pode ser dirigida à política, quando constata-se o predomínio da burocratização e da competividade nesta esfera da vida social e, ainda, o desencantamento, tão bem trabalhado por Weber na reflexão da modernidade.

A aproximação do tema da rede da problemática das relações societárias $e$ do desencantamento possibilita a reflexão dos efeitos sociais da técnica a partir de uma orientação analítica preocupada com o sentido (ou a perda de sentido) da ação. Nesta direção, é importante registrar que Weber (1997) retira do 
âmbito da ação propriamente social seja a ação exterior, que somente se orienta por determinadas expectativas de reações de objetos materiais, seja a conduta íntima, que não se orienta por reações de terceiros. Entretanto, ambas ações emergem, com intensidade, no mundo contemporâneo, em associação com a difusão das novas tecnologias que tanto artificializam quanto intimizam a ação social.

As redes técnicas implicam em ilusões de extra-corporalidade, envolvendo promessas de acesso ao saber, à competência e à ubiqüidade. Constituem, assim, caminhos para a reificação das relações sociais, dada sua natureza aparentemente leve e plástica. Como um molde, aparecem, primeiramente, como um tecido técnico incrustrado no tecido social historicamente constituído.

Neste sentido, as redes enredam, no mesmo momento em que surgem

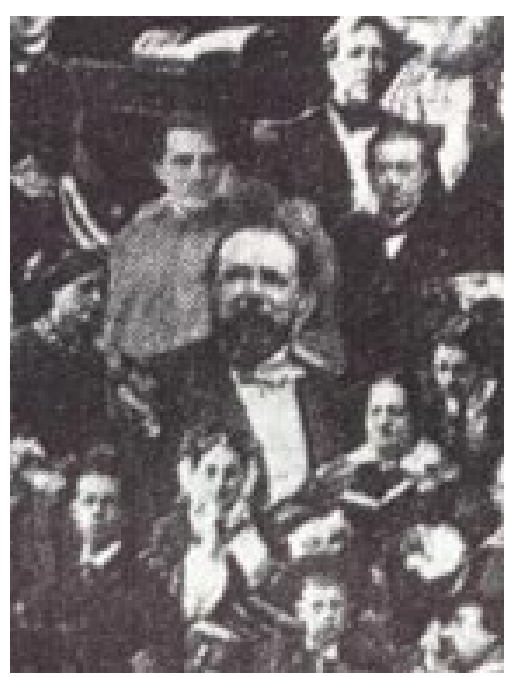
como potencialidades, modificando a ação social, em articulação com expectativas sociais $e$ valores, $e$ a substância do poder.

Trata-se do poder da técnica e da nova técnica do poder, ou seja, da natureza do sistema de ação que valoriza a ação sistêmica, associada ao teor competitivo das relações societárias. Afinal, como dito antes, é impossível pensar a ação social sem simultaneamente refletir o poder, como elemento indissociável da vida social. As redes técnicas têm afinal sua origem nas necessidades dos Estados centrais e das grandes corporações, guardando as marcas de sua origem, como antes os desenhos das estradas de ferro $e$ as rotas das navegações (Dias, 1995).

A multiplicidade de usos, permitida pelas tecnologias contemporâneas, não altera o tipo de ação favorecido nas (e pelas) redes técnicas. Submeter a técnica a ações não instrumentais demanda da sociedade esforços acrescidos que, em geral, não são lidos e nem reconhecidos. As facilidades prometidas pelas novas tecnologias escondem as dificuldades, justificando a adesão a-crítica à ação gestora que encontra, nessas tecnologias, $o$ suporte adequado a sua difusão e legitimação. Existem obstáculos para a ação alternativa que se tornam nítidos quando é observada a acessibilidade aos novos recursos técnicos.

Os obstáculos transparecem na compra obrigatória de elementos irrelevantes para a prática, em incompletudes técnicas continuamente recriadas e na subordinação do usuário à inovação permanente. As redes técnicas possibilitam, ainda, a transformação da comunicação em informação mercantil $e$ a intensificação do ritmo da vida social, o que impede a reflexão, a meditação $e$ a análise. Assim, as redes técnicas, estimuladas pela mídia (onde os apresentadores surgem, agora, acompanhados de laptops), permitem o fechamento de todos os espaços e de todos os tempos, a substituição de redes sociais por redes técnicas, da sociabilidade e da interatividade pela conectividade e, como nos diz Milton Santos, pela competitividade.

Estes elementos materiais e imateriais sustentam a nova natureza do poder, constituindo, simultaneamente, sua forma-aparência. Dominar a técnica (o que, aliás, é quase impossível) surge hoje como promessa de modernização e de modernidade e, ainda, como promessa de acesso ao poder, desejado eterno em sua real substância, já que aparentemente "aberto a todos". Essência $e$ aparência, transformando a questão do poder, surgem imbricadas nas redes técnicas, envolvendo tanto redes sociais historicamente configuradas quanto o sentido hegemônico da ação social.

De fato, a inovação adquire conotações associadas às linguagens e ao 
acoplamento de sistemas técnicos. Desta forma, a ação hegemônica, basicamente instrumental $e$ apoiada numa crescente capacidade de inovar, no contínuo estímulo ao ativismo, condiciona outras ações orientadas por valores ou pelo agir tradicional. As redes são poder, uma forma-aparência do poder, concretizada por mudanças nos sistemas de objetos (Santos, 1996), na criação de produtos e serviços, no predomínio da gestão sobre a ação, na imposição da administração sobre a atividade. As redes são, assim, instrumentos de sistematização da vida coletiva pela ação hegemônica.

Correspondem à manifestação radicalizada da razão, de um certo tipo de racionalidade que conduz a ação dirigida a fins, a ação instrumental, estimulando a burocratização da vida social. De forma contraditória, também correspondem, por tecerem novas relações societárias, a um campo de historicidade (Touraine, 1984) que não pode ser negado e que deve ser rigorosamente disputado. Esta disputa envolve conhecimento, estratégia $e$ domínio de novas linguagens, obrigando a encadeamentos entre atores sociais e políticos, isto é, à construção de forças sociais conscientes dos atuais riscos de fechamento sistêmico - burocrático e banalizador da violência e da exclusão das relações societárias.

Na disputa do novo campo de historicidade, Touraine (1998) sugere, por exemplo, que os conteúdos da ação instrumental não devam ser desconsiderados, já que a ação estratégica "está no mundo", incorporada em sujeitos sociais e na cultura. Por outro lado, a construção identitária propiciada, apenas, pelo lastreamento da ação instrumental não permite a atualização de valores positivos da modernidade, como a igualdade:

Somos todos iguais na medida em que todos procuramos construir nossa individualidade. Em contrapartida, se nos definirmos por nossas ações instrumentais, somos desiguais, dado que um é forte, qualificado ou educado, e o outro é fraco, não qualificado ou analfabeto.

(Touraine, 1998, p.70).

As dificuldades implicadas na disputa do novo campo de historicidade, constituído por técnica e relações societárias, incluem questões relativas à constituição dos atores desta disputa. E esta é uma grande interrogação. Afinal, o novo campo de historicidade encontra-se configurado por elementos materiais $e$ imateriais que, ao mesmo tempo em que facilitam a ação, absorvem ação, dela alimentando-se. Assim, o sistema em gestação apresenta características entrópicas, já que tende a reduzir a totalidade da ação social à ação estratégica dirigida a fins e à atividade ininterrupta, condicionando à velocidade e à abrangência crescentes.

Dar sentido à técnica, subordinando-a à ação conduzida por valores, tornouse atualmente um extraordinário desafio. As forças que conseguirem fazer este movimento, isto é, produzir a mutação do automatismo em sentido, disputarão o poder que emana (e sustenta) o novo sistema social, cujos contornos atualmente apenas se vislumbram. É nesta direção que também deveriam ser estudadas as redes de movimentos sociais, em sua capacidade de atribuir sentido à ação social (Scherer-Warren, 1999). A disputa do novo campo de historicidade pressupõe a subordinação do sistema técnico, e do tipo de ação destilado por este sistema, à complexidade do(s) sistema(s) de ação. Afinal, a disponibilização do dado, tornada indiferente pela extensão da rede técnica,

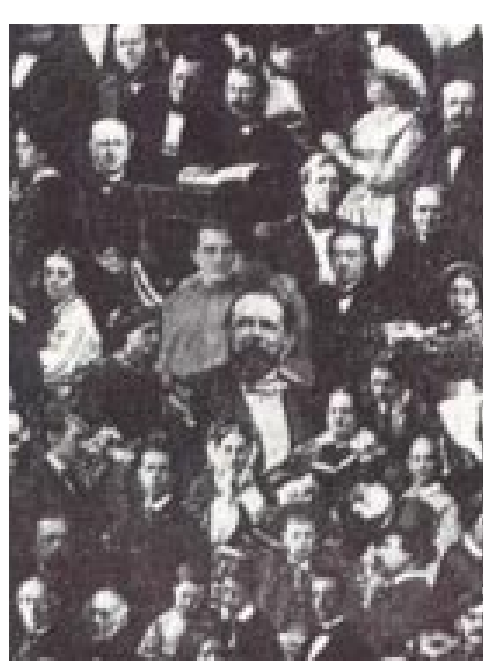


oculta a natureza do poder, que pressupõe a subordinação do dado ao seu significado para a vida social.

No novo campo de historicidade, a disputa de poder caracteriza-se pelo monopólio da informação excepcional, pela sistematização e monitoramento de relações sociais e, também, pelo controle do sentido da ação, o que implica em reconhecer sua articulação ao pensamento único (Santos, 1996; Sader e Gentili, 1995). É a atribuição de sentido que comanda a máquina do mundo, o que desaparece nos discursos da pós-modernidade. Instituições, famílias, grupos sociais e indivíduos têm sido subordinados à nova organização sistêmica da ação social. A questão central é, portanto, saber quem dá sentido à máquina em permanente crescimento, densificação $e$, portanto, corporificação em relações societárias.

Além de um novo tecido comunicante que utiliza processos técnicos anteriores, como exemplificam os chats ou as homepages, existe a configuração sistêmica que, apoiada nas redes técnicas, atribui o sentido predominante à vida em sociedade. Este novo tecido, que é sobretudo meio, obriga ao debate de valores, à recuperação da questão da finalidade da ação social. Na ausência deste momento reflexivo, a administração e o controle tornam-se hegemônicos. É destruída, por este caminho, a racionalidade profunda do fazer, que envolve a reflexão de objetivos e anseios por mudanças substantivas nas relações sociais.

As redes insuflam um novo ritmo à vida coletiva, implicando o

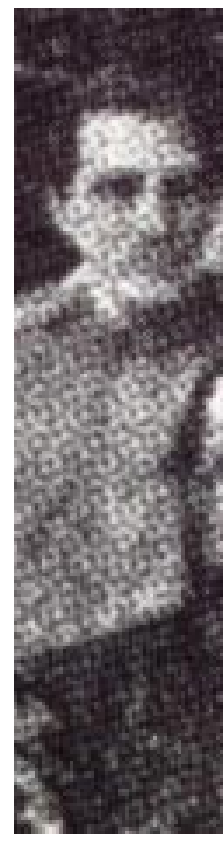
monitoramento da experiência social. Criam simultaneamente racionalidade $e$ irracionalidade, libertam e subordinam. Estimulam, também, a face ativa da sociedade, uma multiplicação interminável de atividades. O stress da vida moderna nunca foi mais verdadeiro, ao mesmo tempo em que são condenadas ao imobilismo enormes parcelas da humanidade.

Nos núcleos expansivos do novo sistema, presentes em diferentes formações sociais, pode-se falar realmente em ativismo, em ativação de relações $e$ relacionamentos, o que corresponde à implantação de verdadeiros atratores de energias sociais e expectativas coletivas. O predomínio da atividade sobre a ação, nestes núcleos, corresponde à redução de valores a instrumentos da ação social. Entretanto, a problemática plena da ação permanece viva, já que articulada à constituição dos sujeitos sociais e ao enfrentamento de dilemas que efetivamente dão sentido à existência humana.

Poder, técnica e resistências sociais

Não é possível acreditar no desaparecimento dos deuses e dos demônios que conduzem a experiência da vida, a não ser numa existência privada de sentido ${ }^{6}$. É, aliás, a percepção dos conteúdos profundos da ação que pode orientar a resistência ao ativismo, à programação, à sistematicidade. Neste sentido, pelas redes também tem sido organizada a resistência às forças hegemônicas contemporâneas, àqueles que, ao dominarem a produção do novo sistema técnico, tentam subordinar o comunicar ao informar, a identidade à imagem, o produzir ao financiar, o espaço ao tempo, a sociedade à técnica.

A resistência à forma atual de exercício do poder impõe o resgate do sujeito plenamente envolto na escolha consciente de valores na orientação de sua conduta. Porém, como reter a burocratização da vida? Como conter a face administrada da existência? Como reconstruir a problemática do homem e suas 
circunstâncias no mundo contemporâneo? Acredita-se que a resposta a este tipo de pergunta dependa da preservação de condições de verdade nas relações societárias, isto é, do alcance de momentos de verdade, sempre transitórios, num contexto instável $e$, ainda mais, efetivamente planejado para ser instável. Estes momentos de verdade, permitindo a escolha de valores, correspondem à orientação ética da ação, revista pelo reconhecimento de características do novo sistema social em processo de consolidação.

A questão do sujeito da resistência aos comandos do novo sistema técnico $e$ do novo sistema de ação pode ser considerada por diferentes caminhos:

(a) enfraquecendo-se o controle permitido pelas redes técnicas, ou mediadas pela técnica, sobre as redes sociais. Esta é uma resistência difícil que pressupõe a recusa à conectividade permanente e ao privilégio do investimento em técnica face ao investimento em gente. Trata-se do controle da mística da técnica pelo pensamento crítico por meio, por exemplo, da desconstrução de crenças que associam, automaticamente, técnica e eficácia, técnica $e$ inteligência, técnica $e$ garantia de futuro;

(b) reconhecendo-se os coletivos criados pelas redes técnicas e aí examinando as novas condições de sujeito. Este seria o caso, por exemplo, dos coletivos ativos que emergem da mundialização dos fluxos financeiros e da extensão das redes de serviços. Podem ser citados, nesta direção, os coletivos ativos com origem nas novas formas de organização dos serviços de saúde (trabalhadores $e$ usuários) e os protestos que têm ocorrido nas reuniões promovidas por agências multilaterais (Davos e Seattle);

(c) estabelecendo-se formas de resistência social à sistematicidade perversa pelos usos transformadores das novas tecnologias. Esta alternativa pressupõe o ensino da técnica em âmbitos sociais inesperados e o desvendamento de usos, também inesperados (não programados), das novas tecnologias;

(d) realizando-se o combate à difusão socialmente destrutiva da técnica. Por exemplo: denúncia do trabalho social não pago envolvido na renovação técnica dos serviços, das formas de segregação social alimentadas por inovações tecnológicas, dos usos hegemônicos de imagens e conhecimentos populares que, no entanto, são desvalorizados pelo pensamento único. Trata-se, aqui, de exigir o retorno social de investimentos feitos num aprendizado imposto;

(e) desestruturando-se ambiências associadas, pelo marketing, à técnica. Esta forma de resistência depende da revalorização da face humana do trabalho $e$, assim, de rupturas em representações sociais correntes que associam, por exemplo, técnica, limpeza (darwinismo social) e status. Neste sentido, as novas tecnologias precisam ser reconduzidas a sua condição de simples instrumentos da ação social, sendo assim liberados os valores;

(f) realizando-se a defesa do acesso socialmente livre às novas condições materiais da vida coletiva. As redes técnicas continuam presas às normas institucionais, aos protocolos de uso, à reprodução da segregação social, ao exercício do poder. Afinal, o acesso social à técnica tem ocorrido quando o poder assim o deseja (por ex: os celulares que esperaram a privatização das "teles" para se tornarem um bem de consumo popular);

(g) exigindo-se o acesso popular à tecnologia de ponta. A segregação social só pode ser superada com o melhor, ou seja, com a tecnologia mais atualizada $e$ que possibilite romper o círculo vicioso da técnica pior para o pior posicionado na estrutura social. Trata-se da garantia de acesso social amplo à nova materialidade, inclusive no nível dos direitos sociais;

\footnotetext{
${ }^{6}$ Nas palavras de Argüelo (1999, p.156) ao

sintetizar uma das linhas

fundamentais da problemática weberiana da modernidade, associada à emergência do indivíduo aprisionado em sua própria subjetividade e isolado de apoios institucionais amplos: "E, não sabemos a quem caberá, no futuro, viver nessa prisão onde não há mais necessidade de justificações éticas e religiosas. Se tudo se

encaminhasse no sentido de uma 'convulsiva espécie de autojustificação', os 'últimos homens' de tal desenvolvimento cultural, ... poderiam ser designados como 'especialistas sem espírito', sensualistas sem coração, nulidades que imaginam ter atingido um nível de civilização nunca antes alcançado".
} 
Sem dúvida, as condições materiais e imateriais do novo sistema social infiltram-se na sociedade histórica. A difusão do tecido técnico novíssimo (Santos, 1996), articulado a transformações no sistema de ação, tende a cindir instituições, classes e grupos sociais. Indicações nesta direção podem ser reconhecidas na reierarquização de posições sociais, em que o conhecimento da técnica ganha relevância sobre outros saberes ou, ainda, por meio do deslocamento de segmentos sociais que passam a vivenciar uma nova velocidade $e$ a usufruir de contatos que os distanciam das condições vivenciadas por seus grupos de origem. A cisão social faz-se acompanhar de outros movimentos expressivos da atualização seletiva do tecido da sociedade.

O sistema social emergente possui formas específicas de apreender e de intervir na sociedade histórica, desenvolvendo suas próprias regras e códigos de comunicação e de avaliação dos recursos disponíveis. É assim que se torna plausível a coexistência de incertezas cada vez mais agudas e certezas permitidas pelo cálculo e pelo desdobramento controlado e monitorado de ações estratégicas. Propondo-se inicialmente como facilitador e agilizador da sociedade histórica, o novo sistema tende a impor-se, gradualmente, como único conteúdo valorizável do Ser social.

Porém, da mesma forma que o tempo não destrói o espaço, já que a matéria resiste a sua transformação em fluxo, a nova instrumentalidade, posta a serviço da ação hegemônica, não destrói a sociedade histórica, que também resiste a sua transformação em fluxo. Esta é uma ilusão tecnicista que não se coaduna com qualquer obervação de senso comum. Afinal, os tempos e espaços do existir continuam envolvidos nas regras e nos limites do cotidiano. Da mesma maneira, a técnica ainda não alcançou oferecer, aos seres humanas, a superação de suas principais angústias: a perda, a dor e a morte.

Além disto, a aceleração de alguns fluxos - associados à renovação exarcebada de determinadas ambiências - pode gerar o retardo de outros, como demonstra a vida urbana, em que a fluidez das novas redes é incompatível com limites também inscritos na materialidade e na sociabilidade, bastando recordar as malhas do trânsito, entre outros processos que, uma vez reunidos, criam irracionalidades no novo corpo social, desejado sistêmico e plenamente eficiente. Entretanto, as irracionalidades, que tanto irritam os usuários das novas tecnologias (como demonstra a frase: como está lento o sistema hoje!), podem ser a salvação do sujeito, já que interrompem fluxos que consomem continuamente a sociabilidade.

Ainda seguindo Weber, é impossível rejeitar as características do mundo racionalizado contemporâneo, a menos que se deseje um retorno extemporâneo ao comunitarismo ou um revival forçado, e até mesmo perigoso, de práticas tradicionais superadas. Entretanto, é igualmente impossível aceitar, sem críticas e sem projetos alternativos, a nova sistematicidade que tenta se impor à experiência social, ignorando contextos sociais $e$ aviltando ideários e memórias. Este dilema contemporâneo, aqui recuperado sob o estímulo da reflexão da noção de rede, impõe o tratamento do sentido da ação, em seus vínculos com a problemática do sujeito e com a preservação de valores como liberdade e igualdade.

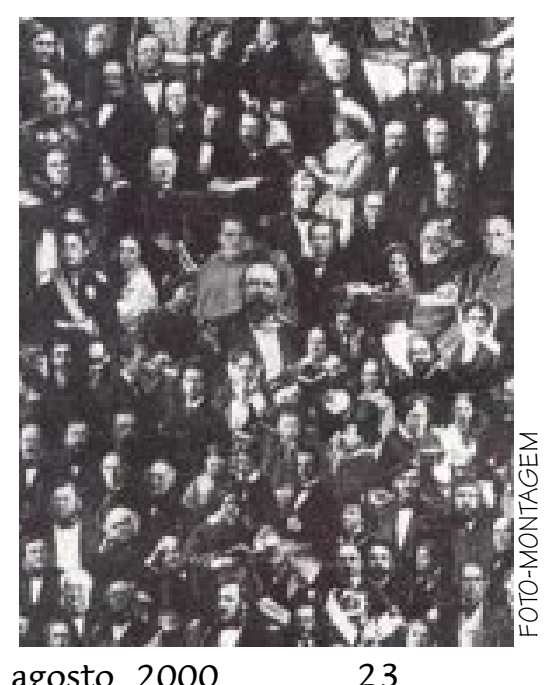

agosto, 2000 


\section{Referências bibliográficas}

ARGÜELLO, K. O mundo perfeito: nem possível, nem desejável. In: SOUZA, J. (Org.) O malandro e o protestante: a tese weberiana e a singularidade cultural brasileira. Brasília: Ed. UnB, 1999.

DIAS, L. Résaux d'information et résaux urbain au Brésil. Paris: Editions L'Harmattan, 1995.

DREIFUSS, R. A época das perplexidades: mundialização, globalização e planetarização: novos desafios. Petrópolis: Vozes, 1996.

GIDDENS, A. The consequences of modernity. Stanford: Stanford University Press, 1990 .

LATOUCHE, S. A ocidentalização do mundo: ensaio sobre a significação, o alcance e os limites da uniformização planetária. Petrópolis: Vozes, 1994.

MAFFESOLI, M. A transfiguração do político: a tribalização do mundo. Porto Alegre: Sulina, 1997. MORIN, E. Ciência com consciência. Rio de Janeiro: Bertrand Brasil, 1996.

PENA-VEIGA, A., NASCIMENTO, E.P. (Org.) O pensar complexo: Edgar Morin e a crise da modernidade. Rio de Janeiro: Garamond, 1999.

RANDOLPH, R. Planejamento urbano e regional. Análise territorial e sistemas de informações geográficas. In: NAJAR, A. L., MARQUES, E. C. (Org.) Saúde e espaço: estudos metodológicos e técnicas de análise. Rio de Janeiro: Editora Fiocruz, 1998.

RIBEIRO, I., RIBEIRO, A.C.T. Família e desafios na sociedade brasileira: valores como um ângulo de análise. Rio de Janeiro: Centro João XXIII, 1994.

SADER, E., GENTILI, P. (Org.) Pós-liberalismo: as políticas sociais e o Estado democrático. Rio de Janeiro: Paz e Terra, 1995.

SANTOS, M. A natureza do espaço: técnica e espaço/razão e emoção. São Paulo: HUCITEC, 1996.

SANTOS, M. Por uma outra globalização: do pensamento único à consciência universal. Rio de Janeiro: Record, 2000.

SCHERER-WARREN, I. Cidadania sem fronteiras: ações coletivas na era da globalização. São Paulo: HUCITEC, 1999.

SOUZA, J. (Org.) O malandro e o protestante: a tese weberiana e a singularidade cultural brasileira. Brasília: Ed. UnB, 1999.

TOURAINE, A. Le retour de l'acteur: essai de sociologie. Paris: Fayard, 1984.

TOURAINE, A. Igualdade e diversidade: o sujeito democrático. Bauru: EDUSC, 1998.

WEBER, M. Economia y sociedad: esbozo de sociologia comprensiva. 2.ed. México: Fondo de Cultura Econômica, 1997.

RIBEIRO, A. C. T. La naturaleza del poder: técnica y acción social, Interface _ Comunicação, Saúde, Educação, v.4 , n.7, p.13-24, 2000.

El texto interroga el carácter polisémico de la noción de red, procurando distinguir los usos actuales de esta noción de los clásicamente formulados por las ciencias sociales. Con base en tal indicación, trata la noción de red por medio de dos opciones analíticas: la reflexión del poder y el contenido de las relaciones societarias estimuladas por las redes técnicas. El análisis ocurre, sobre todo, por la reflexión del sentido de la acción social, registrándose el predominio de la acción instrumental en la modernidad radicalizada.

KEY WORDS: Relaciones interpersonales; modernización tecnologica; redes de comunicación de computadores; poder (Psicología); cambio social. 